\title{
BROADBAND LOW PROFILE AND COMPACT RDRA LOADED WITH METALLIC STRIPS FOR WIDEBAND APPLICATIONS
}

\author{
Hany A. Atallah and Ehab K. I. Hamad \\ Electrical Engineering Department, Aswan Faculty of Engineering, South \\ Valley University, Aswan 81542, Egypt \\ hany.mohamed@asw-eng.svu.edu.eg, e.hamad@ieee.org
}

(Received June 24, 2010 Accepted September21, 2010)

\begin{abstract}
in this paper, a compact broadband, low-profile rectangular dielectric resonator antenna (RDRA) is proposed using relatively low dielectric constant substrate material (Rogers RT/Duroid $\left.3010 \varepsilon_{r}=10.2\right)$ and developed for wireless communication applications. The rectangular DRA is fed with a modified stepped Microstrip feed to ensure efficient coupling between the RDRA and the feeder. Broadband operation is achieved by loading the rectangular dielectric resonator antenna with conducting metallic strip which results in a new resonance beside the antenna operating frequency. The performance of the proposed antenna has been significantly improved by loading the RDRA with two narrow conducting metallic strips of suitable lengths, which results in dual-resonance excitation and leads to a wider operating bandwidth (up to $23.75 \%$ ). The frequency characteristics and radiation performance of the proposed antenna are successfully optimized using numerical experimentation techniques. The antenna size reduction is demonstrated while maintaining a reasonable bandwidth. Simulations results based on a $3 D$ full-wave electromagnetic simulator are presented in the paper.
\end{abstract}

KEYWORDS: RDRA (rectangular dielectric resonator antenna), broadband, loading strips, stepped Microstrip.

\section{INTRODUCTION}

In recent years, the demand for wideband antennas for wireless mobile communications has led to the development of antennas that are low profile and small in size. In the last two decades, Microstrip antennas [1-2] and dielectric resonator antennas (DRAs) [3-5] have been extensively investigated as suitable antennas for wireless communication applications. The DRA offers attractive features such as low ohmic loss, low profile, small size, wide impedance bandwidth as compared to the Microstrip antenna. The DRA can be used at millimeter frequency bands and is compatible with existing excitation methods such as the coaxial probe, microstrip transmission line, coplanar waveguide feed or aperture coupling. DRAs are available in basic shapes such as rectangular, cylindrical, spherical and hemispherical geometries. Rectangular DRAs offer more design flexibility since two of the three of its dimensions can be varied independently for a fixed resonant frequency and known dielectric constant of the material [6]. Hence, we chose the rectangular DRAs for our investigations in this paper. Feeding mechanisms that are generally used for DRAs include using Microstrip lines [7], coaxial probes [8], coplanar waveguide feeds [9] 
and aperture coupling [10]. Coupling techniques that have appeared in the literature [6-10] require the permittivity of the DRA to be high (usually greater than 10) to ensure efficient coupling. Even though high permittivity results in a small DRA, it also narrows the bandwidth. If efficient coupling for relatively low-permittivity, low profile DRAs can be realized, much wider bandwidth can be obtained. Furthermore, inexpensive widely available microwave substrates can be used to make the DRA, rather than commonly used DRAs using high-permittivity ceramic resonators. This is precisely the focus of this research. In this paper, a novel, simple, and efficient coupling technique of low-permittivity, low-profile DRAs, resulting in very broadband performance is presented. Even though in [11] an aperture coupled DRA with a dielectric constant of 10.8 was used; the achieved bandwidth was smaller than the bandwidth obtained with the antenna proposed in this paper which exceeds $21.75 \%$. Techniques published in the literature for high dielectric constant DRAs include two or more stacked DRAs [12], coplanar parasitic DRAs [13], and inclusion of air gaps inside DRAs [14]. Such techniques require additional DRA elements increasing the size of the overall antenna or involve a more complicated geometry than the simple technique presented in this paper. The bandwidth of DR antenna can also be extended by attaching additional parasitic elements to incur another resonance. In this paper, two metal strips are attached to the top of a DR to incur additional resonance close to that of the dielectric resonator. The inductance of the metal strip and the capacitance between the strip and the ground plane form an LC tank circuit which can be coupled to the DR resonant mode to exhibit a wider bandwidth. Also, the impedance bandwidth of DR antennas can be further increased by modifying their feeding structures. In [15], a coupling slot is proposed to excite the DR antenna. The resonant modes of slot and DR are coupled to increase the antenna bandwidth. In this paper a stepped microstrip feed is used to ensure an efficient coupling. The paper first introduces an optimized rectangular DRA and its EM simulations then the EM simulations of the proposed single and dual metallic loading strips RDRA are presented.

\section{RECTANGULAR DRA BACKGROUND}

Usually more resonant modes are observed in a rectangular DRA compared to its cylindrical version over a normalized frequency range. In fact this feature can be used to enhance the bandwidth of the rectangular DRA if adjacent resonant modes have similar radiation patterns. For example, a truncated tetrahedron DRA [16] for wideband applications has recently been realized using this concept. Figure 1 shows the geometry of a stepped microstrip fed rectangular DRA. The rectangular DRA has dimensions $W, L, H$ and dielectric constant $\varepsilon_{r}$, whereas the feeding microstrip has length $L_{1}$ and width $W_{1}$ which ensures a $50 \Omega$ characteristic impedance. The wide strip in essence provides the necessary impedance matching. The feeding stepped strip is placed in the middle under the DRA. The proposed geometry of the low profile DRA fed with a stepped microstrip line through simulations using a commercial 3D fullwave analysis software package Ansoft HFSS [20]. The DRA has a dielectric constant $\varepsilon_{\mathrm{r}}$ and dimensions of length $L=10 \mathrm{~mm}$, width $W=10 \mathrm{~mm}$ and height $H=2.5 \mathrm{~mm}$. The feed microstrip line has a $50 \Omega$ characteristic impedance whereas the width and length of the stepped section are $W_{2}=3 \mathrm{~mm}$ and $L_{2}=10.5 \mathrm{~mm}$, respectively as shown in Fig. 1. The dielectric constants for both the DRA and the feed substrate are chosen to be the 
same. Actually, in the experimental verification part, the DRA was cut from the same substrate used for the feed line. Figure 1 shows the schematic diagram of the designed antenna by stepped microstrip with dimensions $W=10 \mathrm{~mm}, L=10 \mathrm{~mm}$, and $H=2.5$ $\mathrm{mm}$. The substrate used for this simulation was Rogers RT/Duroid 3010 with the thickness of $t=1.27 \mathrm{~mm}$ and a dielectric constant of $\varepsilon_{r}=10.2$ which is commonly used. The unique filler results in a low density, lightweight material for high performance weight sensitive applications, low moisture absorption, uniform electrical properties over frequency and excellent chemical resistance.

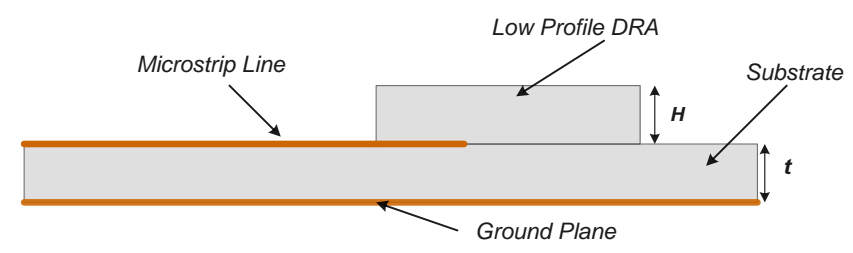

(a) Stepped Microstrip RDRA (Side View)

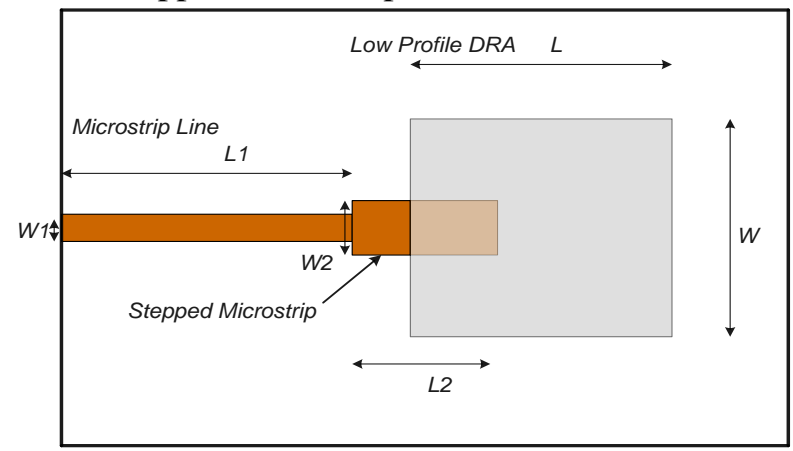

(b) Stepped Microstrip RDRA (Top View)

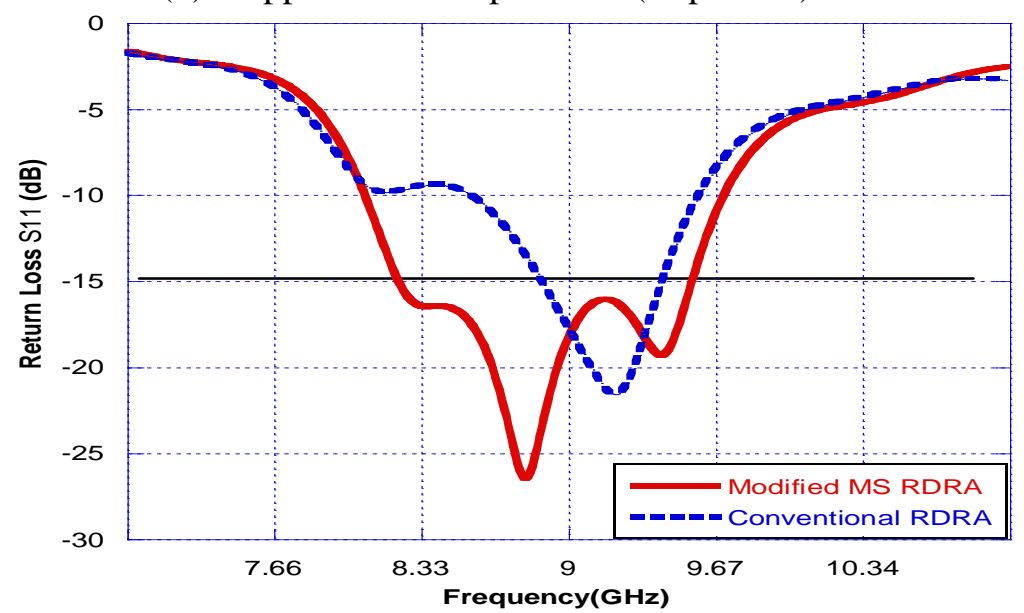

(c) Simulated $S_{11}$ parameters for stepped microstrip RDRA and microstrip RDRA Figure 1: Stepped Microstrip RDRA and Simulated $S_{11}$ parameters

After studying RDRA [17, 18] and by using modified stepped Microstrip, it has been found using experimentation numerical technique, that there is an optimized 
structure that introduces a compact size with high bandwidth. Figure 2 contains the parameters results of the optimized stepped microstrip rectangular DRA.

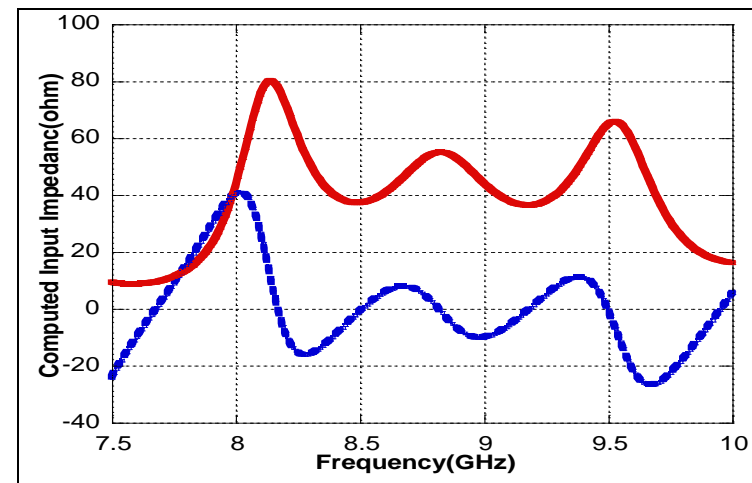

(a) Computed input impedance, - Real and .... Imaginary parts versus frequency.

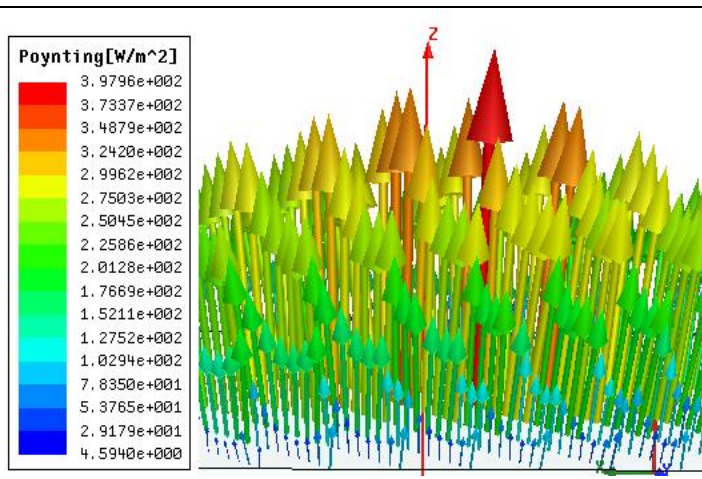

(b) Antenna Poynting vector at $25 \mathrm{~mm}$.

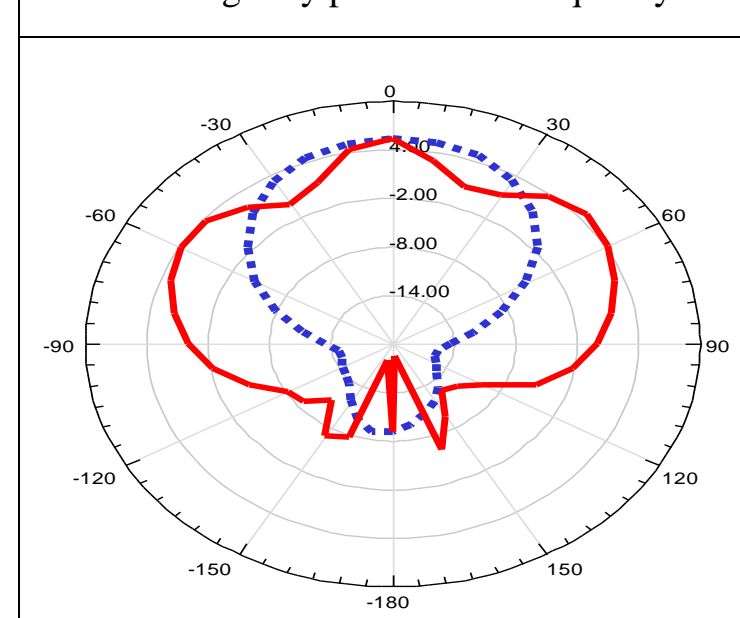

(c) Antenna gain radiation pattern (..... E-plane, _- H-plane)

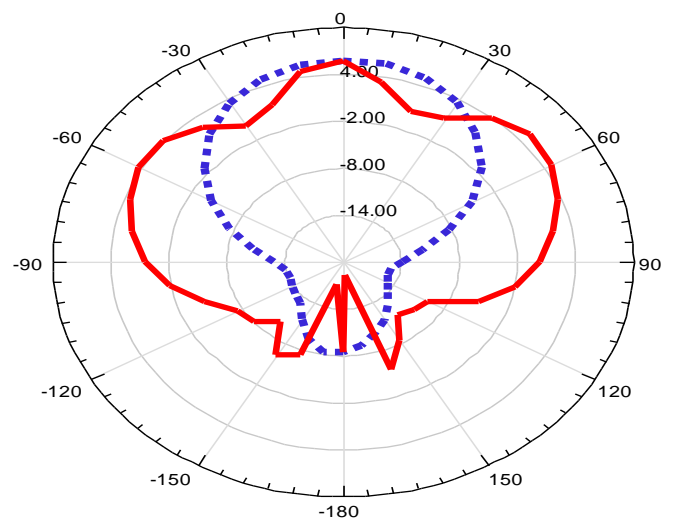

(d) Antenna directivity radiation pattern (..... E-plane, - H-plane)

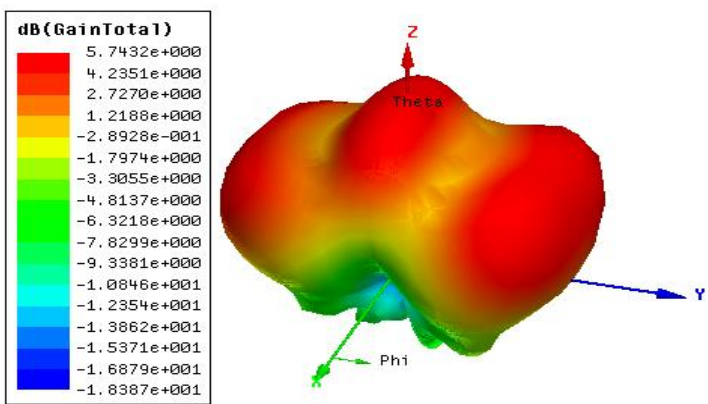

(e) Antenna gain 3D polar plot

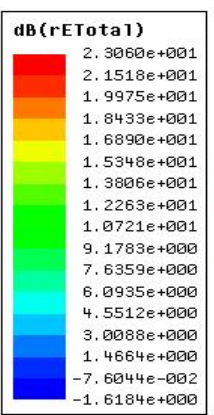

(f) Total electric field 3D polar plot

Figure 2: Optimized rectangular DRA parameters results at $8.8 \mathrm{GHz}$ 


\section{PARAMETRIC STUDIES ON SM RDRA}

Every geometrical parameter has different effects on the overall performances of the proposed antenna. We observed that the width of the metallic strip under the DRA affects extremely its input impedance. A narrow strip width resulted in high input impedance and vice versa. The wide strip provides the necessary impedance matching, if its dimensions width and length are optimized. The DRA has a dielectric constant $\varepsilon_{r}$ $=10.2$ and dimensions of length $L=10 \mathrm{~mm}$, width $W=10 \mathrm{~mm}$ and height $H=2.5 \mathrm{~mm}$. The feed microstrip line has a $50 \Omega$ characteristic impedance whereas the width and in fact stepped section are $W_{2}$ and $L_{2}$.

In the following section, the effects of parameters on the proposed antenna shown in Fig. 1, namely, the slot strip width $W_{2}$; the slot strip length $L_{2}$ and the DRA height will be investigated in depth using EM simulator.

\section{Strip Width Effect:}

To explore the effects of the strip slot width; the DRA antenna is considered without the metallic layer. Figure 3 gives the antenna gain and bandwidth for different strip slot width values. From this study, we found that the relative bandwidth is $18.82 \%$ (1.6 $\mathrm{GHz}$ ) spanning the frequency band from 8.1 to $9.7 \mathrm{GHz}$ when $L_{2}=10.5 \mathrm{~mm}$.
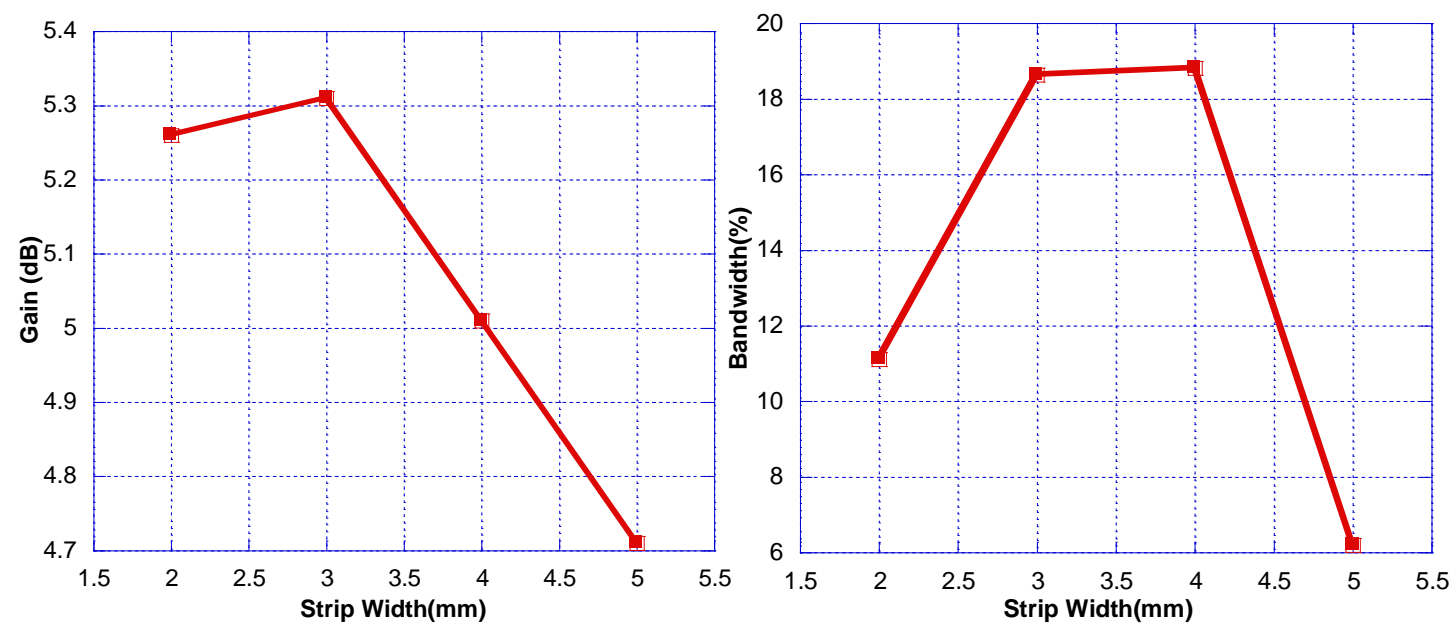

(a) strip slot width effect on antenna gain

(b) strip slot width effect on antenna bandwidth

Figure 3: the effects of the strip slot width

\section{Strip Length Effect:}

To explore the effects of the strip slot length; the DRA antenna is considered without the metallic layer. Figure 4 gives the antenna parameters for different strip slot length values. From this study, we found that the relative bandwidth is $18.82 \%$ spanning the frequency band from 8.1 to $9.7 \mathrm{GHz}$ when $W_{2}=3 \mathrm{~mm}$. 

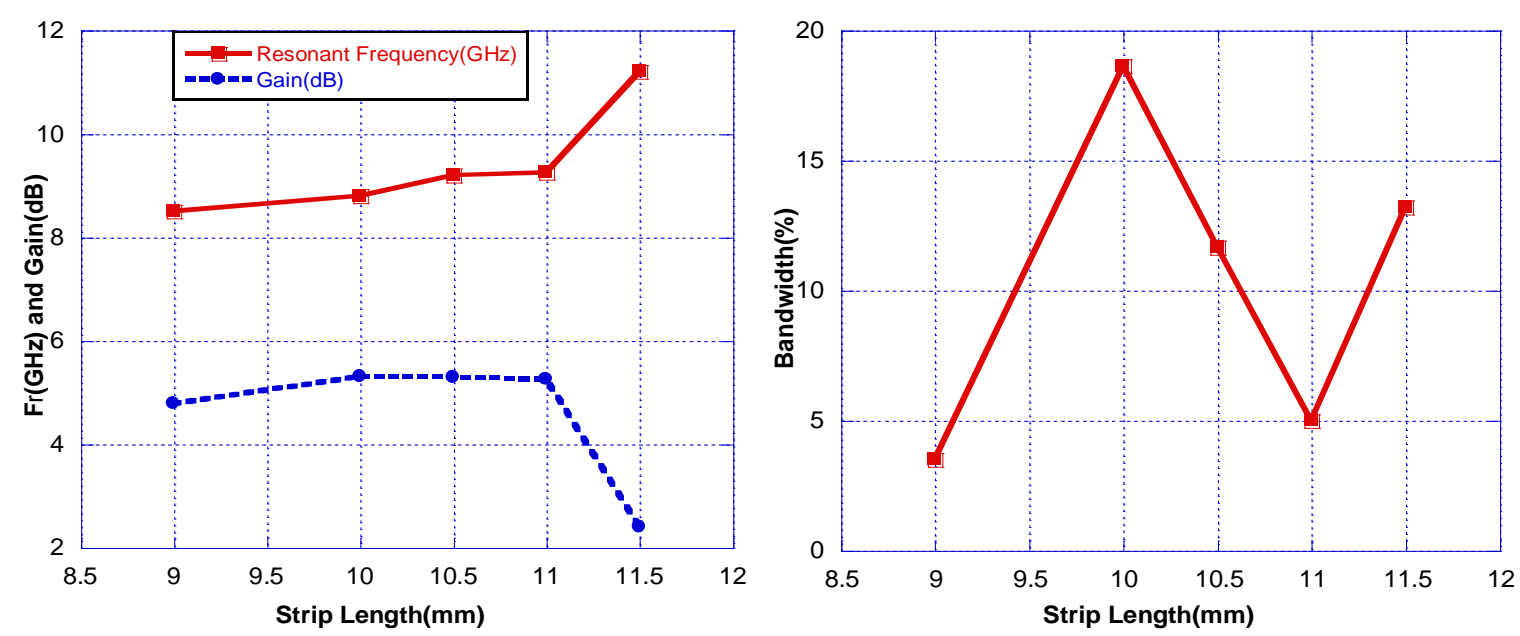

(a) strip length effect on antenna gain and $F_{r}$

(b) strip length effect on antenna bandwidth

Figure 4: The effects of the strip slot length

\section{DRA Height Effect:}

In Fig. 5, the antenna parameters are depicted as a function of the DRA height as a parameter. Following several optimization simulations shown in Fig. 5, we found that DRA height equal to $1.9685 \times H$ to enhance the bandwidth of this antenna. From this figure, we can see that the height of the RDRA affects the resonant frequency which decreases when DRA height increases .by using numerical analysis techniques to fit the curve with least squares straight line approximation, the following equation is obtained:

$$
f_{r}=12.517-1.5 \times H
$$

Where $f_{\mathrm{r}}$ is the resonant frequency in $\mathrm{GHz}, H$ is the rectangular DRA height in $\mathrm{mm}$ and $R=0.99926$ is the correlation factor.
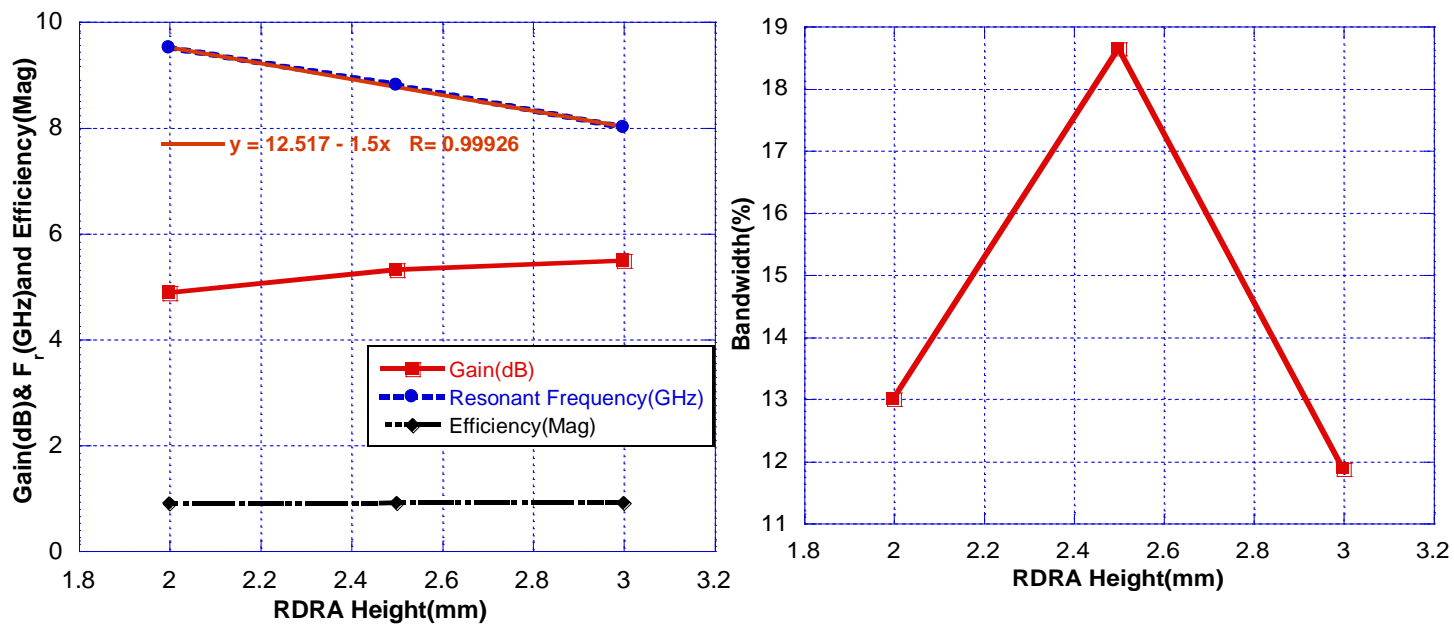

(a) DRA height effect on antenna gain, $f_{\mathrm{r}}$

(b) DRA height effect onand efficiency bandwidth

Figure 5: the effects of the RDRA height 


\section{Optimized Structure:}

According to the above analyses; it is obvious that the strip width of the microstrip rectangular is the most effective parameter to control the bandwidth of the proposed antenna as shown on Fig. 1. The optimized DRA parameters values obtained by simulations are: $H=2.5 \mathrm{~mm}, W_{2}=3 \mathrm{~mm}, L_{2}=10.5 \mathrm{~mm}$. The dielectric constant value $\left(\varepsilon_{r}=10.2\right.$ for both DRA and substrate) is the same as the one used in literature [6]. Figure 1-c demonstrates the simulation results of the return loss of the optimized antenna versus frequency. The HFSS simulations' results show that the relative bandwidth achieved with optimal parameters is about $18.82 \%$ ranging from $8.1 \mathrm{GHz}$ to $9.7 \mathrm{GHz}$.

\section{PROPOSED SINGLE METALIC STRIP SM RDRA}

The proposed geometry of the low profile DRA fed with a Stepped Microstrip (MS) line and with metallic strip is shown in Fig. 6 through simulations using a commercial full-wave analysis software package. The metallic strip over the DRA affects significantly its gain and bandwidth. A metal strip on the DRA disturbs the shield current and it can change the effective inductance and capacitance of the DRA. A narrow stepped microstrip width resulted in a high input impedance, much higher than $50 \Omega$, whereas a wide strip lowered the input impedance of the DRA; hence the proposed geometry. The wide strip in essence provides the necessary impedance matching, if its dimensions width and length are optimized. The DRA has a dielectric constant $\varepsilon_{r}$ and dimensions of length $L$, width $W$ and height $H$. The feed microstrip line has a $50 \Omega$ characteristic impedance whereas the width and length of the stepped section are $W_{2}$ and $L_{2}$, respectively as shown in Fig. 6. The dielectric constants for both the DRA and the feed substrate are chosen to be the same. Actually, in the experimental verification part, the DRA was cut from the same substrate used for the feed line. As will be shown in Fig. 6, the proposed configuration produced an impedance bandwidth better than $19.6 \%$ using numerical experimentation technique. A metal strip on the DRA disturbs the shield current and it can change the effective inductance and capacitance of the DRA. The substrate used for this simulation was Rogers RT/Duroid 3010 with the thickness of $t=1.27 \mathrm{~mm}$ and a dielectric constant of $\varepsilon_{r}=10.2$. DRA dimensions are, $W=10 \mathrm{~mm}, L=10 \mathrm{~mm}, H=2.5 \mathrm{~mm}$ and the metal strip width on the DRA $S W=2 \mathrm{~mm}$.

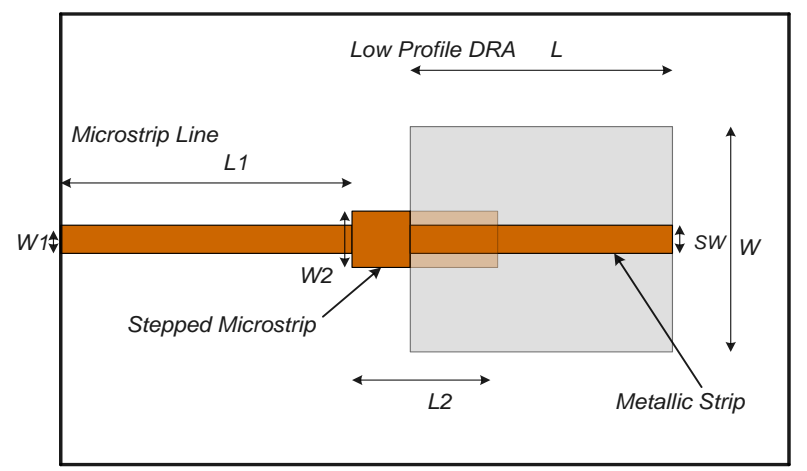

(a) Proposed single metal slot RDRA (Top View) 


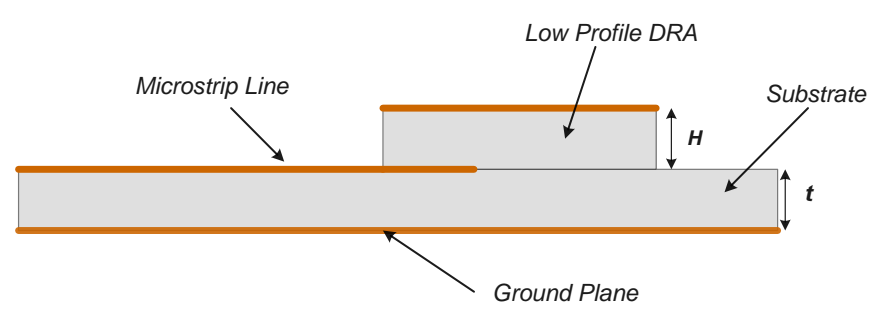

(b) Proposed single metal slot RDRA (Side View)

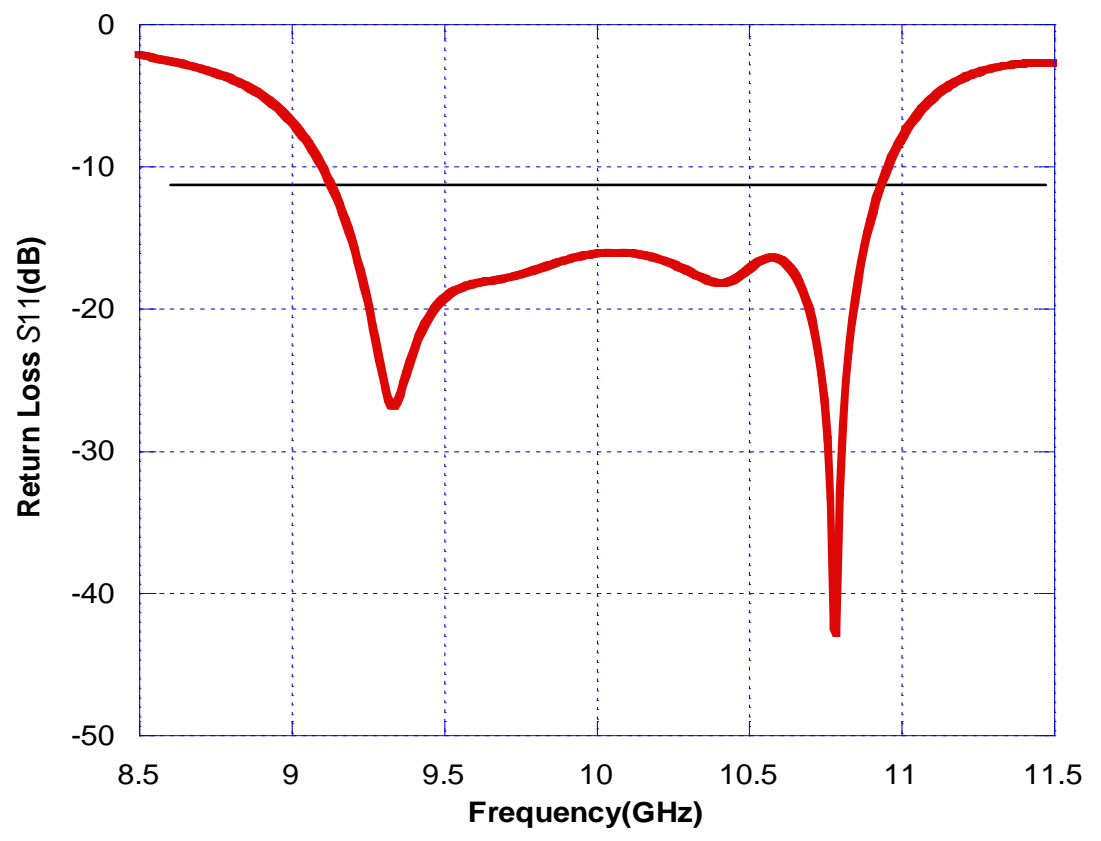

(c) Simulated $S_{11}$ parameters

Figure 6: Proposed single metal slot RDRA and the simulated $S_{11}$ parameters

After studying stepped microstrip RDRA using single metallic slot, it has been found that the proposed antenna introduces a compact size with high bandwidth. Figure 7 contains the antenna parameters results.

Figure 7 contains the parameters results of the optimized broadband single metallic strip rectangular DRA which produces a bandwidth up to $19.6 \%(1.8 \mathrm{GHz})$ form (9 to 11) GHz suitable for wideband wireless communication applications at Xband with gain improvement up to $6.1 \mathrm{~dB}$, efficiency up to $90.5 \%$ and directivity up to $6.53 \mathrm{~dB}$.

\section{PARAMETRIC STUDIES ON SM METALLIC RDRA Metallic Slot Layer Width Effect:}

To increase the bandwidth; a rectangular metallic layer is placed in the middle of the DRA. After several optimization tests, we found that the metallic layer length and width are $(10 \mathrm{~mm}, 1 \mathrm{~mm})$ to get a larger bandwidth. The optimal value obtained for the 
antenna bandwidth is $19.6 \%$. Figure 8 shows that gain and directivity of the antenna nearly remains unchanged; while the bandwidth significantly increased as strip width decreased.

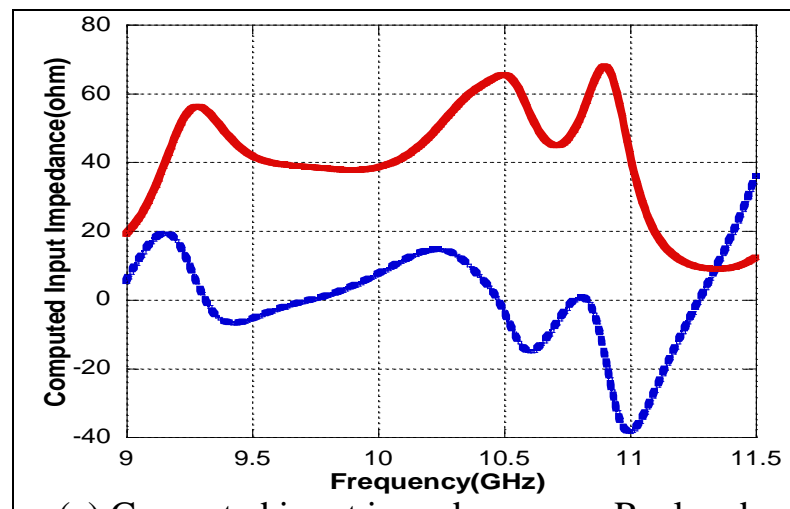

(a) Computed input impedance, - Real and .... Imaginary parts versus frequency.

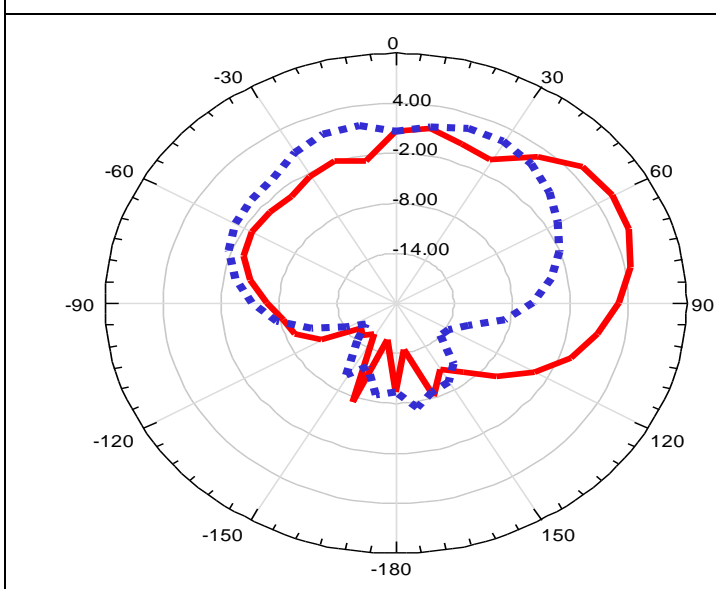

(c) Antenna gain radiation pattern (..... E-plane, — H-plane)

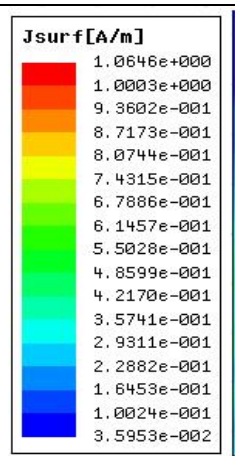

(b) Total current density $(\mathrm{A} / \mathrm{m})$ on $\mathrm{x}-\mathrm{y}$ plane at $25 \mathrm{~mm}$.

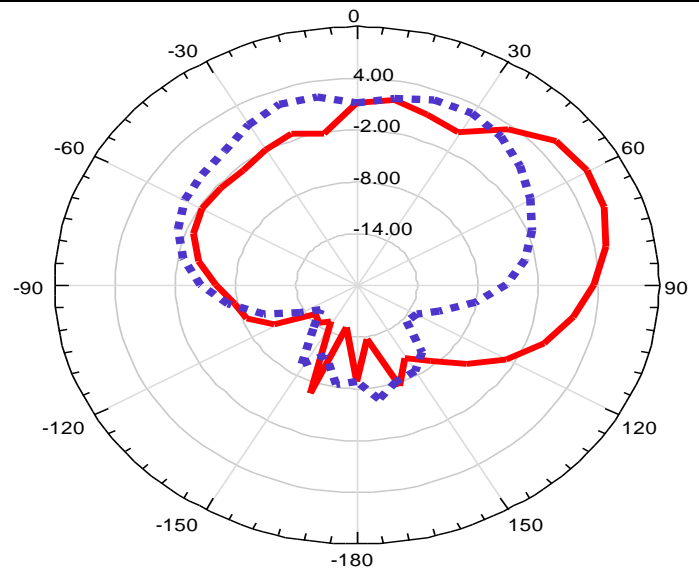

(d) Antenna directivity radiation pattern (..... E-plane, — H-plane)

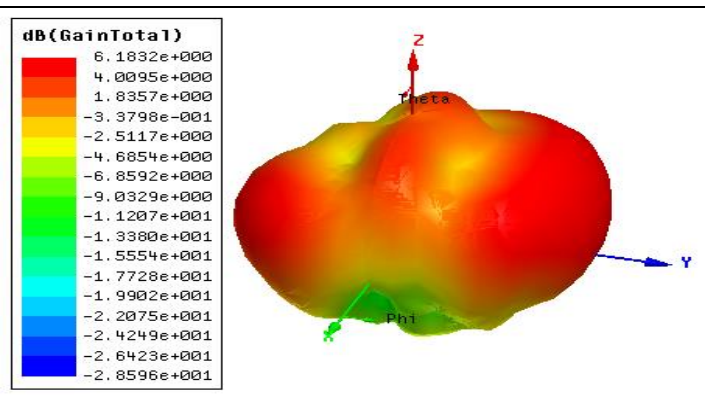

(e) Antenna gain 3D polar plot

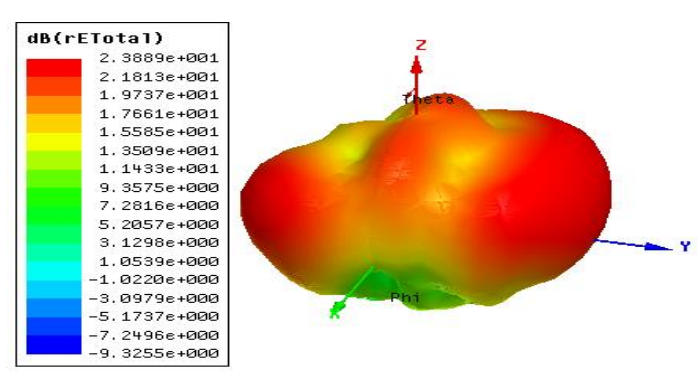

(f) Total electric field 3D polar plot

Figure 7: Optimized single metal patch Rectangular DRA parameters results 


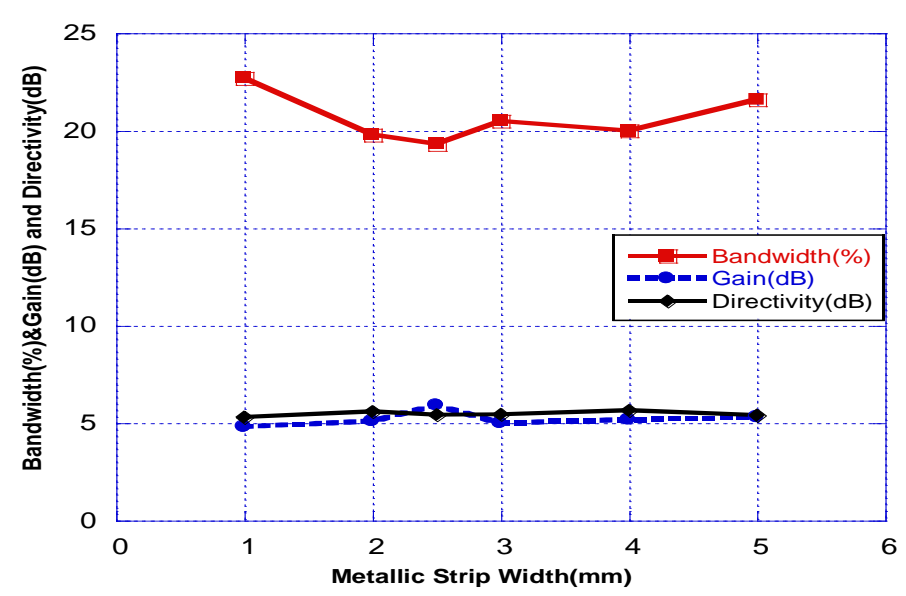

Figure 8: the effects of the metallic strip width

\section{PROPOSED DOUAL METALIC STRIP RDRA}

The proposed geometry of the low profile DRA fed with a stepped microstrip line and with double metallic strip is shown in Fig. 9. Through extensive simulations as will be shown in Fig. 9-b, the proposed configuration produced an impedance bandwidth better than $23.5 \%$. The metallic strip is a slot over the RDRA. This metallic slot disturbs the current distribution in the DR antenna. The proposed metallic RDRA unit section can provide cutoff frequency and attenuation zero in some frequency. The metallic slot increases the effective permittivity leading to an increase in the effective inductance and capacitance of the microstrip line. Therefore, the metallic slot can be modeled as a parallel LC resonance circuit. A more accurate model of the metallic slot would include an extra capacitance and inductance which result due to the fringing fields around the discontinuity area. The circuit parameters for the derived equivalent circuit can be extracted from the simulation results as described in [19]. The schematic diagram of the designed antenna with stepped microstrip is shown in Fig. 9-a. The antenna dimensions are; $W=10 \mathrm{~mm}, L=10 \mathrm{~mm}, H=2.5 \mathrm{~mm}$. The substrate used for this simulation was Rogers RT/Duroid 3010 with the thickness of $t=1.27 \mathrm{~mm}$ and a dielectric constant of $\varepsilon_{r}=10.2$.

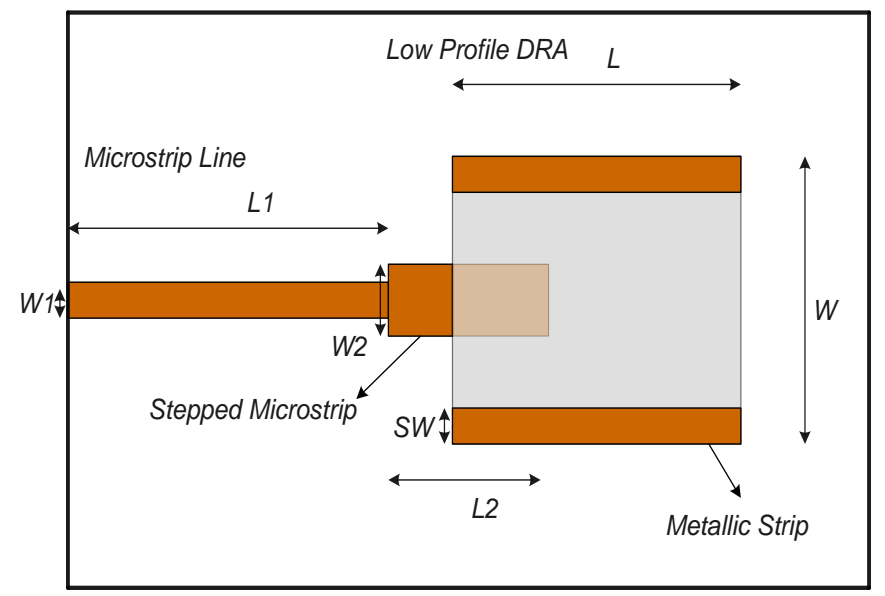

(a) Double metallic strip (Top View) 


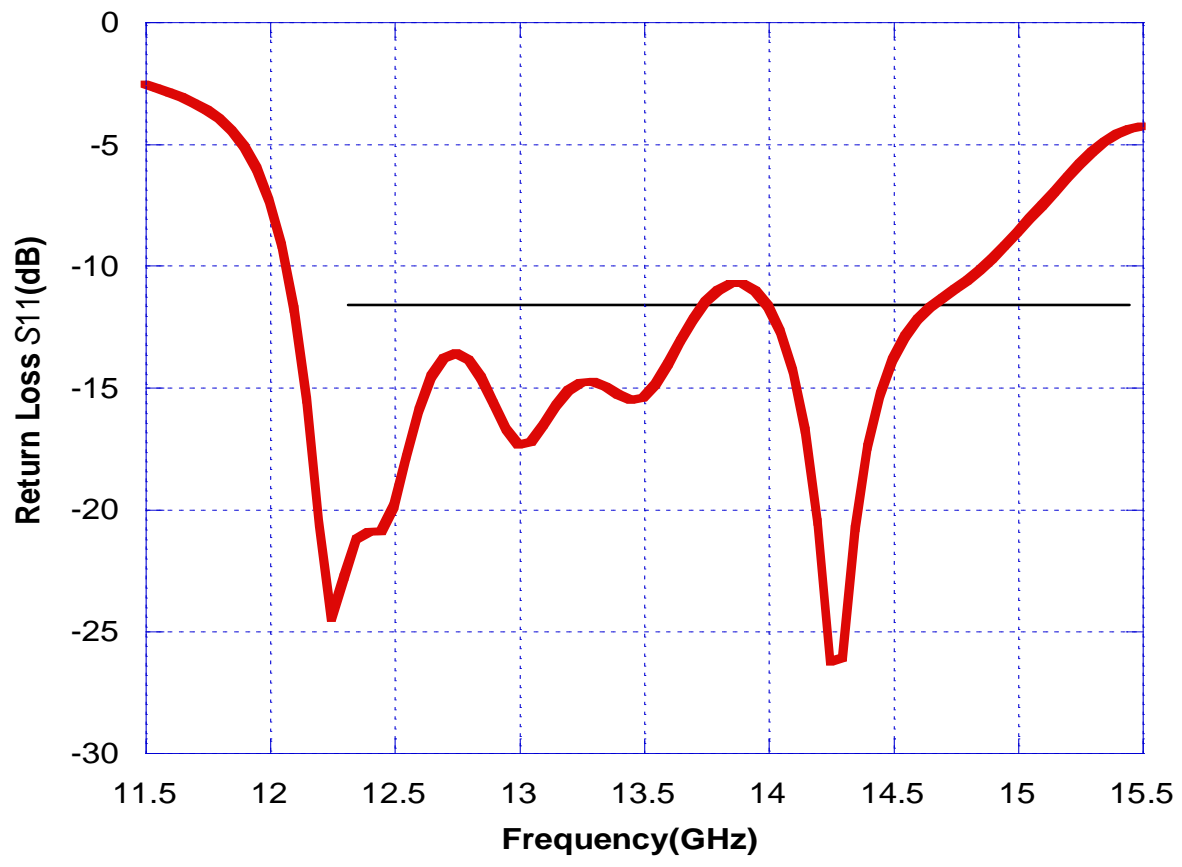

(b) Simulated $S_{11}$ parameters

Figure 9: Double metallic strip and EM simulations

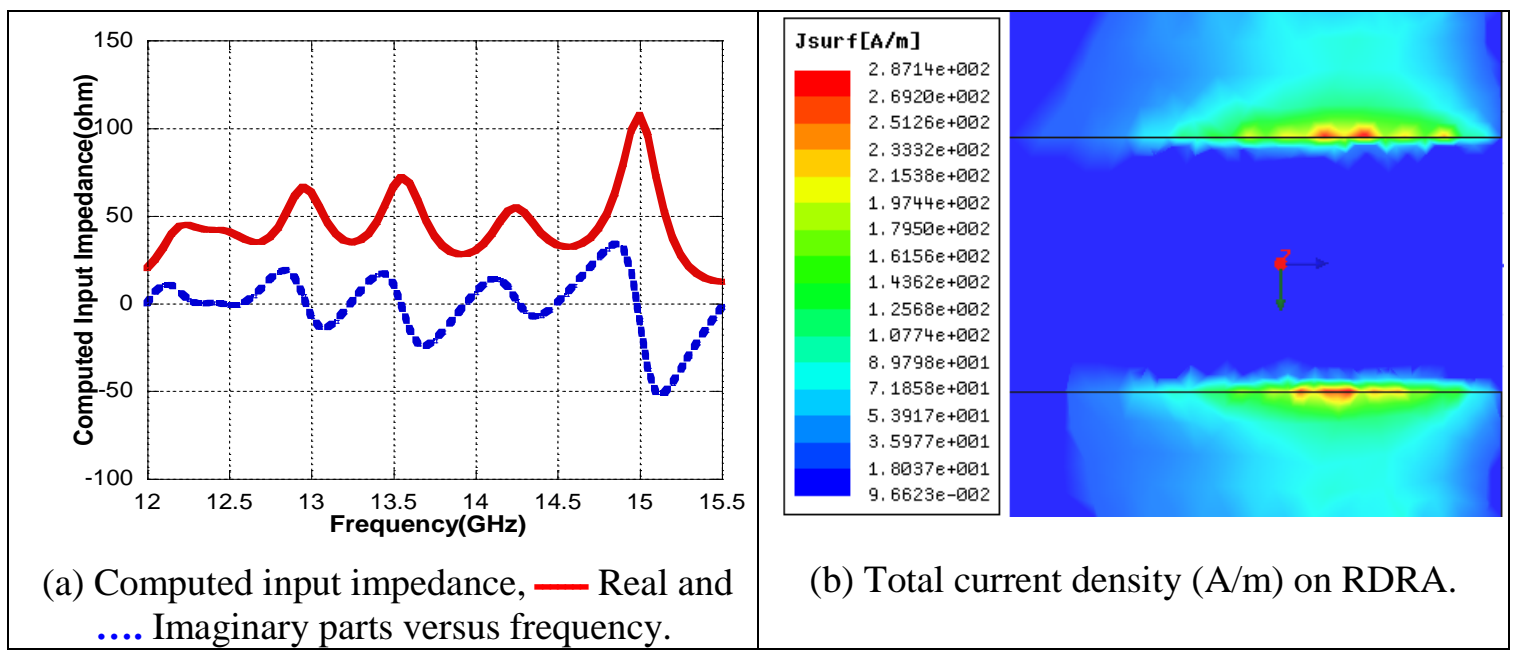




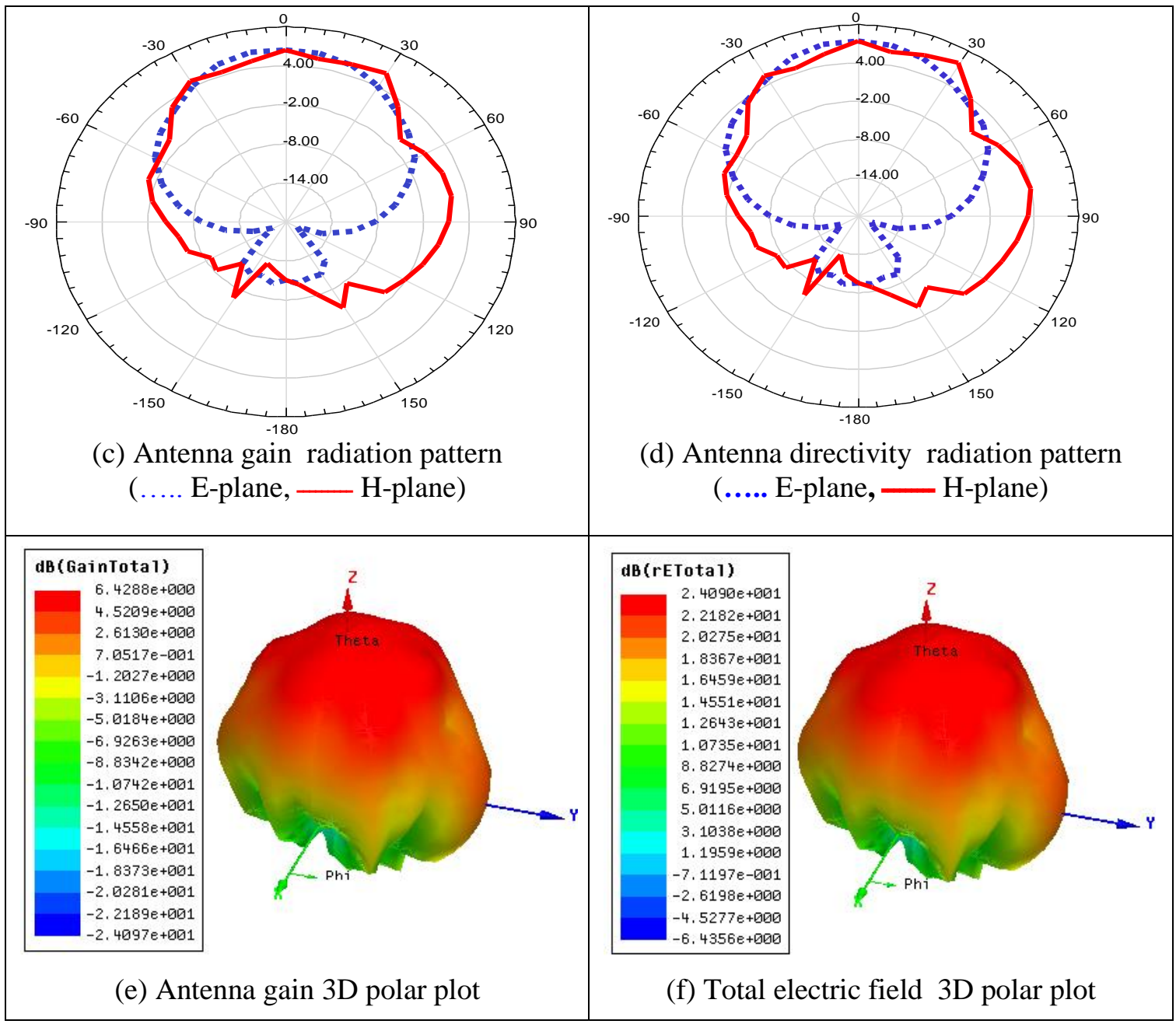

Figure 10: Optimized dual metal strip rectangular DRA parameters results

Figure 10 illustrates the parameter results of the optimized broadband SM double metallic strip rectangular DRA. Which produces a bandwidth up to $23.75 \%$ (2.9 $\mathrm{GHz}$ ) form (12 to 15) $\mathrm{GHz}$ suitable for wideband wireless communication applications at Ku-band with gain improvement up to $7.7 \mathrm{~dB}$ and directivity up to $8.6 \mathrm{~dB}$.

Size reduction was demonstrated while maintaining a reasonable bandwidth $(23.7 \%)$. by reducing the antenna size to $\left(45 \times 60 \mathrm{~mm}^{2}\right)$. Figure 11 shows the gain and directivity of the proposed dual metallic strip RDRA and its reduced size. The proposed antenna offers a peak gain of $\sim 7.7 \mathrm{~dB}$ and an average gain of $\sim 6.65 \mathrm{~dB}$ while the reduced size offers a peak gain of $\sim 6.6 \mathrm{~dB}$ and an average gain of $\sim 5.2 \mathrm{~dB}$ in the operating band. 


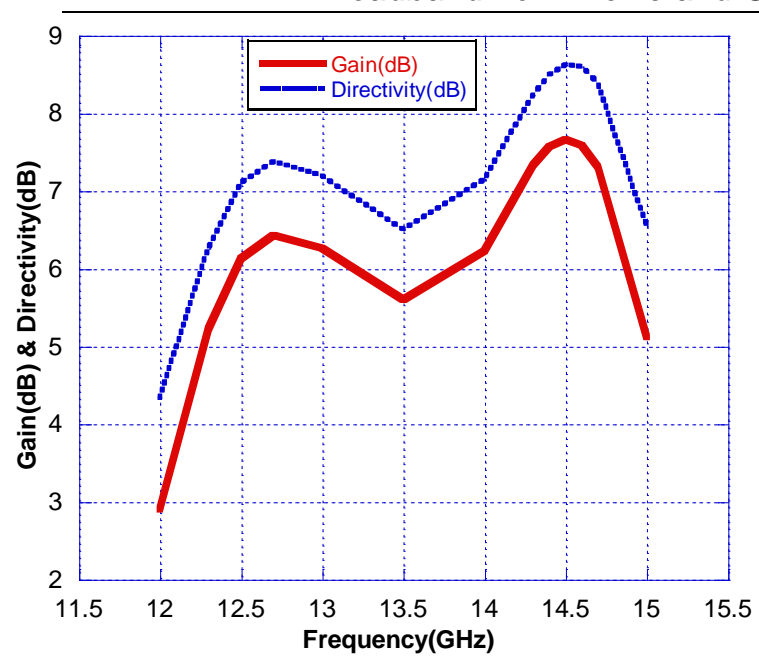

(a) the proposed antenna gain and directivity directivity

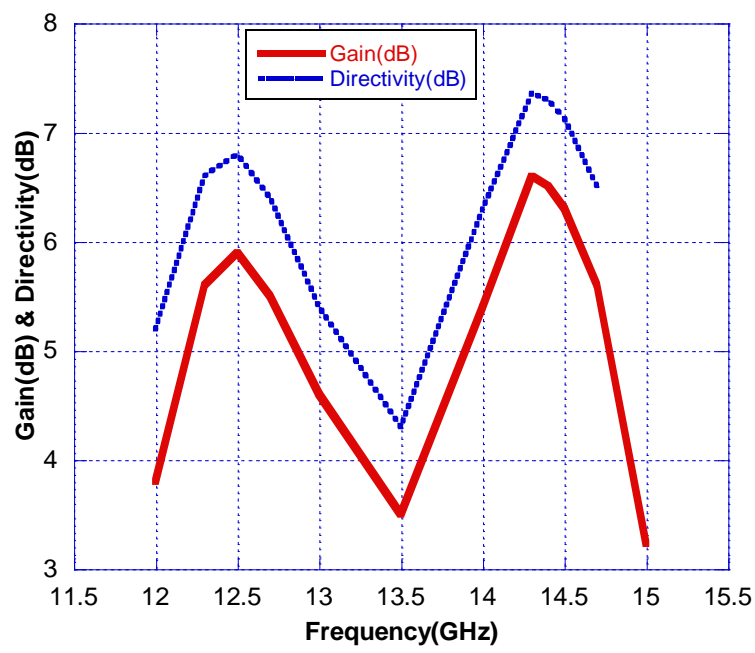

(b) the reduced size antenna gain and

Figure 11: The effects of the antenna size on gain and directivity in the operating band

\section{CONCLUSIONS}

In this paper, a design of a new broadband rectangular DRA antenna has been presented. By adding a metallic strip on the RDRA and stepped microstrip for enhancing the matching, the bandwidth and the gain of the proposed antenna has been significantly improved. A parametric investigation of the different variables has also been presented, and the obtained results show that the proposed antenna can produce a bandwidth of $23.75 \%$. The radiation patterns are stable over the operating frequency range. With this feature, the proposed antennas are suitable for broadband wireless systems at X-band and Ku-band.

\section{REFERENCES}

[1] M. Ali, R. Dougal, G. Yang, and H. S. Hwang, "Wideband Circularly Polarized Microstrip Patch Antenna for Wireless LAN Applications", IEEE Antennas and Propagation International Symposium Digest, Vol. 2, 34-37, June 2003.

[2] M. T. Islam, M. N. Shakib, N. Misran, T. S. Sun, "Broadband Microstrip Patch Antenna", European Journal of Scientific Research, Vol. 27 No. 2, pp.174-180, 2009.

[3] K. M. Luk, and K. W. Leung, "Dielectric Resonator Antennas", Research Studies Press Ltd Press, Baldock, Herfordshire, UK, 2002.

[4] G. D. Makwana and K. J. Vinoy, "Design of a Compact Rectangular Dielectric Resonator Antenna at 2.4GHz", Progress In Electromagnetics Research C, Vol. 11, 69-79, 2009.

[5] S. Sreekantan, Y. K. Ling, and Z. A. Ahmad, "Simulation and Experimental Investigators on Rectangular, Circular and Cylindrical Dielectric Resonator Antenna", Progress In Electromagnetics Research C, Vol. 7, 151-166, 2009. 
[6] Qinjiang Rao ,Tayeb A. Denidni and Abdel R. Sebak, "Study of Broadband Dielectric Resonator Antennas", Progress In Electromagnetics Research Symposium 2005 piers.mit.edu, Hangzhou, China, August 22-26, 2005.

[7] R. A. Kranenburg and S. A. Long, "Microstrip Transmission Line Excitation of Dielectric Resonator Antennas", Electronics Letters, Vol. 24, No. 18, 1156-1157, September 1988.

[8] A. A. Kishk, X. Zhang, A. W. Glisson, and D. Kajfez, "Numerical Analysis of Stacked Dielectric Resonator Antenna Excited by a Coaxial Probe for Wideband Applications", IEEE Trans Antennas Propagation, Vol. AP-51, 1996-2003, 2005.

[9] M. S. Al Salameh, Yahia M. M. Antar, and Guy Seguin, "Coplanar Waveguide Fed Slot Coupled Rectangular Dielectric Resonator Antenna", IEEE Transactions on Antennas and Propagation, Vol. 50, No. 10, October 2002.

[10] R. Chair, S. Lung S. Yang, A. A. Kishk, K. F. Lee, and K. M. Luk, "Aperture Fed Wideband Circularly Polarized Rectangular Stair Shaped Dielectric Resonator Antenna”, IEEE Transactions on Antennas and Propagation, Vol. 54, No. 4, April 2006.

[11] Karu P.Esselle, "A Low Profile Rectangular Dielectric Resonator Antenna", IEEE Transactions on Antennas and Propagation, Vol. 44, No. 9, 1296-1297, September 1996.

[12] Y. F. Ruan, Y. X. Guo, and X. Q. Shi1, "Wideband Dielectric Resonator Antenna", Microwave and Optical Technology Letters, Vol. 48, No. 2, February 2006.

[13] R. N. Simons and R. Q. Lee, "Effect of Parasitic Dielectric Resonators on CPW /Aperture Coupled Dielectric Resonator Antennas", IEEE Proceedings-H, Vol. 140, No. 5, October 1993.

[14] A. Petosa, N. Simons, R. Siushansian, A. Ittipiboon, and M. Cuhaci, "Design and Analysis of Multisegment Dielectric Resonator Antennas", IEEE Transactions on Antennas and Propagation, Vol. 48, No. 5, May 2000.

[15] A. Buerkle, K. Sarabandi, and H. Mosallaei, "Compact Slot and Dielectric Resonator Antenna with Dual-Resonance Broadband Characteristics", IEEE Transactions on Antennas and Propagation, Vol. 53, No. 3, March 2005.

[16] A. A. Kishk, "Tetrahedron and Triangular Dielectric Resonator with wideband Performance", IEEE Antennas and Propagation International Symposium, Vol.4, pp 462-465, June 2002.

[17] R. K. Mongia and A. Ittipiboon, "Theoretical and Experimental Investigations on Rectangular Dielectric Resonator Antennas", IEEE Transactions Antennas Propagation, Vol. 45, No. 9, September 1997.

[18] A. A. Kishk, "Experimental Study of Broadband Embedded Dielectric Resonator Antennas Excited by a Narrow Slot", IEEE Antennas and Wireless Propagation Letters, Vol. 4, 79-81, 2005.

[19] Y. F. Ruan,Y. X. Guo, and X. Q. Shi1, "Equivalent Circuit Model of TriResonance Wideband Dielectric Resonator Antenna", Microwave and Optical Technology Letters ,Vol. 49, No. 6, June 2007.

[20] Ansoft Corporation, HFSS, http://www.ansoft.com/products/hf/hfss /. 


\section{هوائي العازل الرنان المستطيل المحكم ذو نطاق التردد الواسع و المظهر المنخفض}

\section{والمحمل بقطعة معدنية طويلة لتناسب تطبيقات النطاق العريض}

هوائي العازل الرنان المسنطيل المحكم ذو نطاق التردد الواسع و المظهر المنخفض المُقترح باستخدام

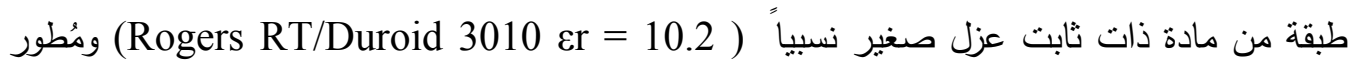

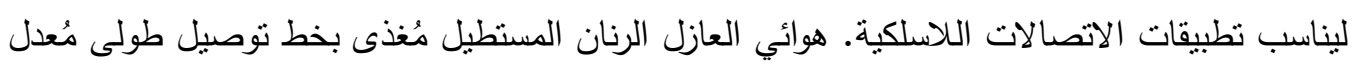

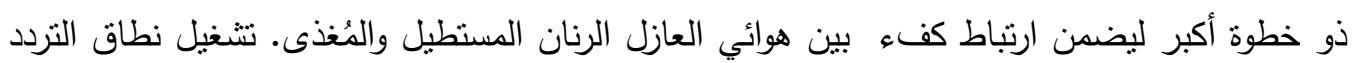

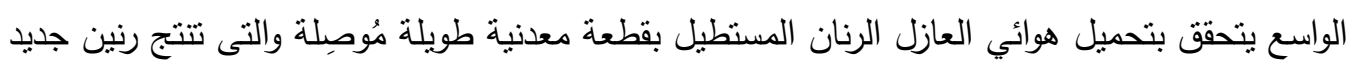
بجوار تردد تشغيل الهوائي. تم تحسين آداء الهوائي بشكل ملحوظ. تم تحميل هوائي العازل الرنان

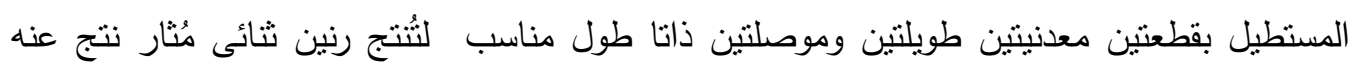

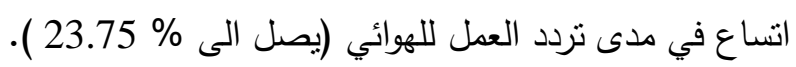

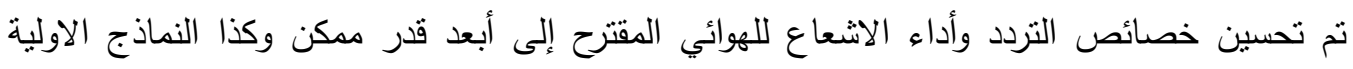

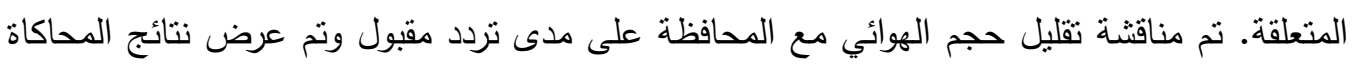
التي تؤيد الفكرة المطروحة بالبحث باستخدام البرامج التجارية المعتمدة. 